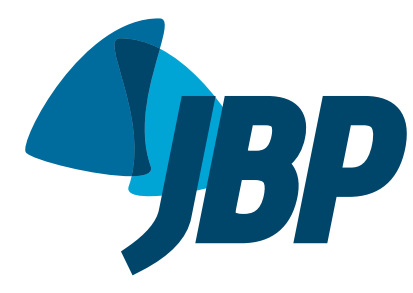

1. Secretaria de Estado de Saúde de Mato Grosso, Cuiabá (MT) Brasil.

2. Universidade Estadual Paulista "Júlio de Mesquita Filho" - Unesp - Marília (SP) Brasil.

3. Universidade Federal de Mato Grosso, Cuiabá (MT) Brasil.

4. Instituto de Saúde Coletiva. Universidade Federal de Mato Grosso, Cuiabá (MT) Brasil.

Submitted: 9 December 2014. Accepted: 8 April 2015

Study carried out under the auspices of the Secretaria de Estado de Saúde de Mato Grosso, Cuiabá (MT) Brasil.

\section{Depression, anxiety, stress, and motivation over the course of smoking cessation treatment}

\author{
Maritza Muzzi Cardozo Pawlina1, Regina de Cássia Rondina², \\ Mariano Martinez Espinosa ${ }^{3}$, Clóvis Botelho ${ }^{4}$
}

\begin{abstract}
Objective: To evaluate changes in the levels of patient anxiety, depression, motivation, and stress over the course of smoking cessation treatment. Methods: This cohort study involved patients enrolled in a smoking cessation program in Cuiabá, Brazil. We selected patients who completed the program in six months or less ( $n=142$ ). Patient evaluations were conducted at enrollment (evaluation 1 [E1]); after 45 days of treatment with medication and cognitive-behavioral therapy (E2); and at the end of the six-month study period (E3). Patients were evaluated with a standardized questionnaire (to collect sociodemographic data and determine smoking status), as well as with the University of Rhode Island Change Assessment scale, Beck Anxiety Inventory, Beck Depression Inventory, and Lipp Inventory of Stress Symptoms for Adults. The data were analyzed with the nonparametric Wilcoxon test for paired comparisons. To compare treatment success (smoking cessation) with treatment failure, the test for two proportions was used. Results: Among the 142 patients evaluated, there were improvements, in terms of the levels of anxiety, depression, motivation, and stress, between E1 and E2, as well as between E1 and E3. In addition, treatment success correlated significantly with the levels of motivation and anxiety throughout the study period, whereas it correlated significantly with the level of depression only at E2 and E3. Conclusions: We conclude that there are in fact changes in the levels of patient anxiety, depression, motivation, and stress over the course of smoking cessation treatment. Those changes appear to be more pronounced in patients in whom the treatment succeeded.
\end{abstract}

Keywords: Anxiety; Depression; Motivation; Cognitive therapy; Smoking cessation.

\section{INTRODUCTION}

Smoking is now considered a chronic disease caused by nicotine dependence and is one of the main risk factors for various diseases. Exposure to tobacco smoke, either through the direct consumption of tobacco or its derivatives or in the environment (second-hand smoke), causes roughly 6 million deaths a year and is considered a worldwide health problem. ${ }^{(1)}$ Despite the high prevalence of smoking in some countries, there has been an overall decrease in the number of smokers in recent decades, possibly due to public policies that have been implemented, together with increased access to smoking prevention and treatment. Annual reductions in smoking prevalence have been reported: $0.6 \%$ in Japan; $0.7 \%$ in the United States; and $0.8 \%$ in the United Kingdom. In Brazil, the prevalence of smoking declined from $32 \%$ in 1989 to $17.1 \%$ in 2008 , representing a reduction of $0.78 \%$ per year. ${ }^{(2)}$

Despite the general advances in smoking control, the high rates of treatment failure in smoking cessation programs constitute a cause for concern. (3) Among the various complicating factors are high levels of anxiety, depression, and stress, as well as a low level of motivation for change, on the part of patients who seek treatment via smoking cessation programs. ${ }^{(3-5)}$ Most of the currently available forms of smoking treatment have some weaknesses, and researchers have been seeking new approaches in order to improve the success rates of smoking cessation programs.

Consensuses and guidelines for smoking cessation interventions suggest that combining psychological support and the use of first-line pharmacotherapy (with nicotine replacement therapy, bupropion, or varenicline) increases the chances of treatment success. ${ }^{(3)}$ Cognitive-behavioral therapy (CBT) is an important psychological intervention for the treatment of the nicotine dependence itself and plays a pivotal role in successfully treating and restructuring the lives of smokers. ${ }^{(6)}$

Smokers who decide to quit but are unable to do so on their own are the ones who seek out health care services for treatment. Among those, only $3 \%$ succeed in quitting without the aid of CBT and medication, and there is always a significant proportion of patients who relapse. ${ }^{(3)}$ For smokers who seek treatment at specialized centers, the process of quitting is arduous, especially while coping with the ambivalence that nicotine dependence entails. They are aware of the harm that smoking causes but

Correspondence to:

Maritza Muzzi Cardozo Pawlina.

Rua Santiago 22, apto. 102, Ed. Royal Princess, Jardim das Américas, CEP 78060-628, Cuiabá, MT, Brasil.

Tel. 5565 3613-5471. E-mail: maritzamuzzi@terra.com.br

Financial support: None. 
continue smoking because of their great dependence on the drug. ${ }^{(3)}$

Some patients are able to quit smoking with minimal suffering, whereas others try several times and are unable to quit. It is possible that certain individual characteristics, such as those related to the psychological state of the patient, are responsible for these different profiles. There could be changes in the levels of patient anxiety, depression, motivation for change, and stress during the process of smoking cessation. ${ }^{(5)}$ Therefore, the present study was aimed at evaluating the influence of the interventions typically applied (medications and CBT) on factors believed to make smoking cessation more difficult.

\section{METHODS}

This was a cohort study in which the patients evaluated were over 18 years of age and spontaneously sought out the smoking cessation program at one of four health care facilities in the city of Cuiabá, Brazil: the Campo Velho Health Center; the Júlio Müller University Hospital; the Coxipó Multidisciplinary Clinic; and the Planalto Multidisciplinary Clinic. All smokers who enrolled in one of those programs between May and August of 2012 were invited to participate in this study.

There were 216 smokers who initially agreed to participate in the study. Of those, 74 (34.26\%) abandoned the program before the end of the six-month study period and $142(65.74 \%)$ completed the treatment within that period, the latter group therefore comprising the study population. As shown in Figure 1, the patients were evaluated at three different time points: at the initial evaluation (at enrollment), designated evaluation 1 (E1), at the mid-treatment evaluation (after 45 days of treatment with medication and CBT), designated evaluation 2 (E2), and at the end of the six-month study period, designated evaluation 3 (E3).

During the initial interview, the patients were evaluated by the physician responsible for the program and subsequently received the appropriate medication. They were also submitted to an initial psychological evaluation by the lead researcher (a psychologist), who applied the various psychometric instruments, counseled the patients in relation to the proposed treatment plan, and scheduled the first CBT session.

After data collection at E1, the patients were invited to attend four weekly 90-min group CBT sessions (1015 patients each). As has been recommended, (7) they were also offered the option to attend five follow-up sessions, at $15,30,60,90$, and 180 days after the initial four-week treatment period.

The instruments employed were as follows:

- a standardized questionnaire, in two parts: Part I-sociodemographic profile; and Part II-smoking status, including data related to the smoking history, number of cigarettes smoked per day, and age at onset of the smoking habit

- the Fagerström Test for Nicotine Dependence
(FTND), ${ }^{(8,9)}$ patients scoring above the mean being considered highly dependent on nicotine

- the University of Rhode Island Change Assessment (URICA) scale, ${ }^{(10,11)}$ which is used in order to assess the level of motivation for change (stage of change) in patients, who were thus categorized as being in the precontemplation/contemplation or preparation/action stages

- the Beck Anxiety Inventory (BAI), ${ }^{(12,13)}$ which consists of a list of 21 common symptoms characteristic of anxiety, the level of anxiety in our patients thus being categorized as minimum/mild or moderate/severe

- the Beck Depression Inventory (BDI), ${ }^{(13,14)}$ which comprises 21 items scored on a fourpoint scale, with scores of 0-3 corresponding to increasing degrees of severity of depression, which was thus categorized in our patients as minimum/mild or moderate/severe

- the Inventário de Sintomas de Stress para Adultos de Lipp (ISSL, Lipp Inventory of Stress Symptoms for Adults), (15) developed for use in Brazil, which (on the basis of physical and psychological symptoms) identifies stress and stratifies it by phase (alarm, resistance, near exhaustion, and exhaustion), our patients thus being dichotomized into a stress group and a no stress group

In the second and third evaluations (phases 2 and 3 , respectively), the same psychometric instruments (URICA, BAI, BDI e ISSL) were again applied.

The FTND, URICA scale, BAI, and BDI have all been translated to Portuguese and validated for use in Brazil. $(9,11,13)$ Although the URICA scale was validated in illicit drug users, ${ }^{(11)}$ it can also be considered valid for smokers in Brazil.

The data were checked and were double entered into the EpiData program, version 3.1 (EpiData Association, Odense, Denmark), after which they were analyzed in the statistical programs STATA, version 13.0 (StataCorp LP, College Station, TX, USA) and the Statistical Package for the Social Sciences, version 17.0 (SPSS Inc., Chicago, IL, USA). The data were initially analyzed descriptively, with measurements of position and variation (mean, median, and standard deviation), as well as with box plots. Subsequently, an inferential analysis was carried out, and the data distribution was observed. For continuous variables without normal distribution, we used nonparametric tests (e.g., the Wilcoxon test) to make paired comparisons. The Wilcoxon test for paired samples was used in order to determine whether the measurements of the position of two samples were equal, if the samples were dependent. ${ }^{(16)}$ In all comparisons, a level of significance of 0.05 ( $p<0.05$ ) was adopted. To compare treatment failure with treatment success (smoking cessation), we performed an inferential analysis of the data, comparing two proportions (when the distribution was normal) and calculating the respective $95 \%$ confidence intervals. To determine the magnitude of the difference between two proportions, 


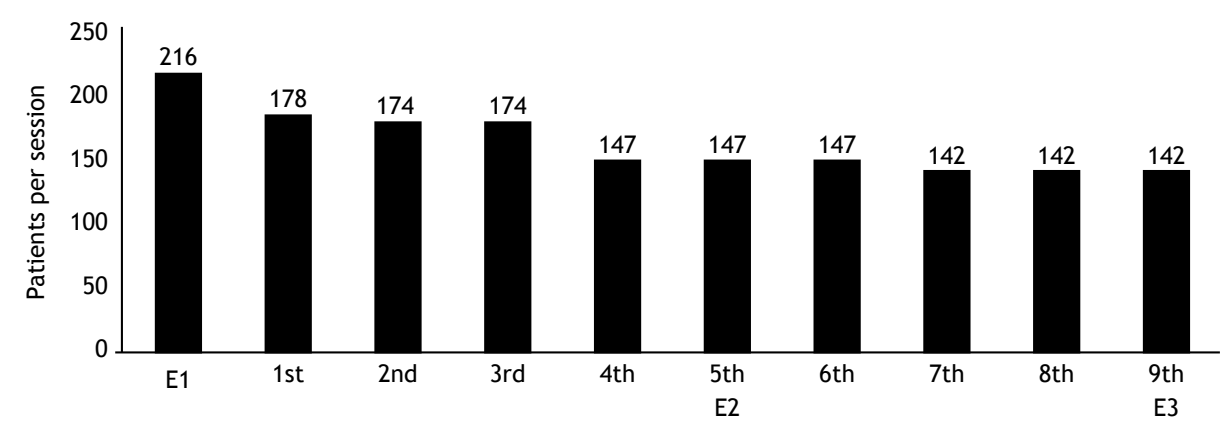

CBT sessions

Figure 1. Number of patients attending cognitive behavioral therapy (CBT) sessions over the course of a six-month smoking cessation treatment program in the city of Cuiabá, Brazil, 2013. E1: initial (baseline) evaluation; E2: midtreatment evaluation (after 45 days of treatment with medication and CBT; and E3: final evaluation (and at the end of the treatment period).

we used the test for two proportions, with a level of significance of $0.05(\alpha<0.05) \cdot(17,18)$

This study was evaluated and approved by the Research Ethics Committee of the Júlio Müller University Hospital (Protocol nos. 0106612.6.0000.5541 and 19548). All participating patients gave written informed consent.

\section{RESULTS}

All of the participants were treated with the same protocol: nicotine replacement therapy, bupropion, and CBT. Among those who completed the six-month treatment protocol, the treatment success rate was $57.04 \%$.

In the study sample, there was a predominance of females, who accounted for $100(70.42 \%)$ of the 142 participants; 90 of the participants $(63.38 \%)$ were between 40 and 59 years of age; 79 (55.63\%) had no steady partner; 127 (89.44\%) had children; 101 $(71.13 \%)$ had had over 8 years of schooling; and 81 (57.04\%) were currently employed. Regarding monthly family income, 66 (46.48\%) of the participants earned less than three times the national monthly minimum wage, which was, in Brazilian reals ( $R \$), R \$ 622.00$ at the time of the interview. Of the 142 patients evaluated, $114(80.28 \%)$ had smoked for 20 years or more; 56 (39.44\%) smoked 11-20 cigarettes/day; and $98(69.01 \%)$ had a FTND score $\geq 6$ (indicating high or very high nicotine dependence).

Of the 142 patients who completed the six-month treatment protocol, 81 (57.04\%) were able to quit smoking. Of those 81 patients, $53(65.4 \%)$ chose to quit abruptly ("cold turkey").

Figure 2 shows the distribution of the patients by stage of change category (based on the URICA scale scores) at the three time points evaluated. At $E 1,20.42 \%$ of the sample (29 patients) were in the preparation/action stages, and that proportion rose to $82.39 \%$ ( 117 patients) by E3. In addition, the proportions of patients with URICA scale scores indicative of the precontemplation/contemplation stages were significantly lower at E2 and E3 than at E1 ( $p<0.001$ for both), although the difference between E2 and E3 was less than significant ( $p=0.499)$.

As depicted in Figure 3, the mean BAI scores in phases 1,2 , and 3 were $17.58 \pm 11.44$ (median, 16.00), $13.02 \pm 10.22$ (median, 11.00), and $12.61 \pm$ 10.75 (median, 10.00), respectively. In comparison with the BAI scores recorded at $E 1$, those recorded at E2 and E3 were significantly lower ( $p<0.001$ for both), although no such difference was observed between E2 and E3.

Figure 4 shows the BDI scores at all three time points evaluated. The mean BDI scores at E1, E2, and E3 were $16.01 \pm 9.99$ (median, 14.00), $11.87 \pm 9.13$ (median, 10.00), and $10.55 \pm 9.58$ (median, 8.00), respectively. The scores were significantly lower at E2 and E3 than at E1 ( $p<0.001$ for both), as well as being significantly lower at E3 than at E2 ( $p=0.003)$.

Figure 5 shows the distribution of the patients stratified by the level of stress (stress vs. no stress, based on the ISSL scores) at the three time points evaluated. In comparison with $\mathrm{E} 1$, the proportion of patients in the stress group was significantly lower at $E 2$ and $E 3$ ( $p=0.002$ and $p=0.025$, respectively). However, the difference between E2 and E3 was less than significant ( $p=0.662)$.

Table 1 details the differences between the patients who continued to smoke and those who did not, over the course of the treatment, stratified by whether or not the treatment was eventually successful, in terms of the level of motivation for change (URICA scale scores), level of anxiety (BAI scores), severity of depression (BDI scores), and level of stress (ISSL scores). As can be seen in the table, the treatment was more likely to fail if patients remained in the preparation/action stages of change until E3 ( $p<$ 0.001 ; $\triangle$ URICA, -40.98); continued to have minimum/ mild anxiety until E3 ( $p=0.0007 ; \Delta B A I,-18.80)$; or exhibited minimum/mild symptoms of depression at $E 2(p=0.0007 ; \Delta B D I,-19.61)$ or at $E 3(p=0.0007$; $\triangle B D I,-17.99)$. However, the level of stress (ISSL score) did not have a statistically significant effect on 


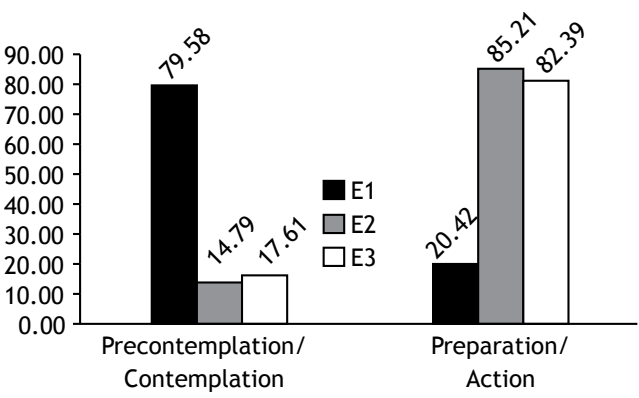

Figure 2. Distribution of patients by level of motivation (stage of change category, based on the University of Rhode Island Change Assessment scale scores) at the three time points evaluated during a six-month smoking cessation treatment program in the city of Cuiabá, Brazil, 2013.

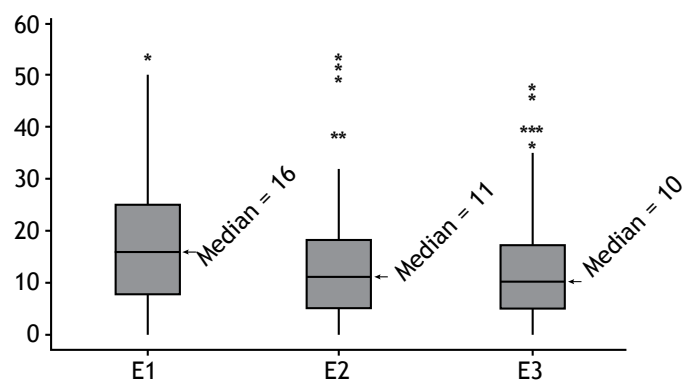

Figure 3. Distribution of patients by level of anxiety (based on the Beck Anxiety Inventory scores) at the three time points evaluated during a six-month smoking cessation treatment program in the city of Cuiabá, Brazil, 2013. *Outlier.

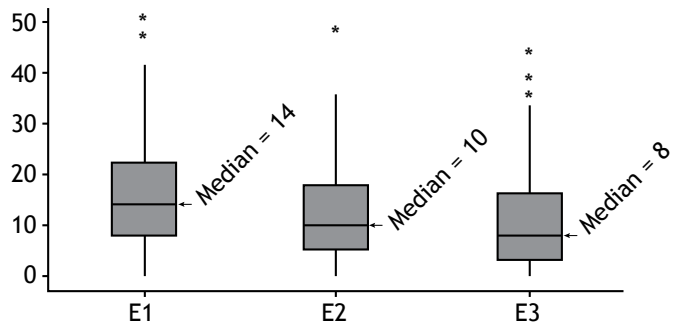

Figure 4. Distribution of patients by severity of depression (based on the Beck Depression Inventory scores) at the three time points evaluated during a six-month smoking cessation treatment program in the city of Cuiabá, Brazil, 2013. *Outlier.

the outcome of the treatment or on the propensity of smokers to relapse over the course of the treatment period. Although quitting smoking apparently contributed to the significant reductions in symptoms, the absolute increase in the differences between $\mathrm{E} 1$ and the subsequent evaluations indicates that the effects of the interventions were also significant.

\section{DISCUSSION}

In the present study, we observed that the number of patients who transitioned from the precontemplation/

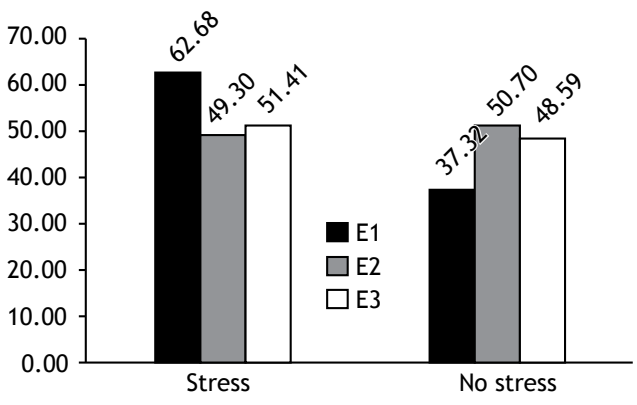

ISSL

Figure 5. Distribution of patients by level of stress (stress category), based on the Inventário de Sintomas de Stress para Adultos de Lipp (ISSL, Lipp Inventory of Stress Symptoms for Adults) scores, at the three time points evaluated during a six-month smoking cessation treatment program in the city of Cuiabá, Brazil, 2013.

contemplation stages of change to the preparation/ action stages was greatest between E1 and E2, the period in which the CBT portion of the intervention was most intense (weekly sessions). Therefore, it is possible that the CBT, rather than the bupropion, was responsible for that change. Other authors who evaluated the effectiveness of CBT in smoking cessation treatment have suggested the same. ${ }^{(19)}$

Our findings serve to alert health care professionals who enroll and treat patients in cessation programs to the need to focus on patient motivation, because the majority of smokers seeking help are not truly ready to quit smoking. Strengthening patient motivation is essential to encouraging behavioral changes, and it is fundamental to focus on the ambivalent behavior of smokers who want to quit smoking but simultaneously feel incapable of doing so. ${ }^{(20)}$ Therefore, it is suggested that the health professionals involved in the dynamics of the cessation process conduct a motivational interview, using individualized therapeutic interventions for smokers who are unmotivated or unprepared and ambivalent, encouraging them to reflect upon and make changes in their behavior so that they can advance to the action stage. (21) Miller \& Sanchez defined six motivational elements that are essential to making such changes: feedback (provide feedback); responsibility (emphasis on patient responsibility); advice (direct counseling to achieve changes); menu (alternatives, options, and choices); empathy; and self-efficacy (patients must believe in their own capacity to change). ${ }^{(22)}$ This is in accordance with the transtheoretical model of behavior change, the main assumption of which is that successful self-initiated changes are related to the application of the right strategies (processes) at the right time (stages). ${ }^{(23)}$

Another important finding of the present study was the change in the BAI scores over the course of smoking cessation treatment (reductions from E1 to E2 and from E1 to E3). There have been few studies of changes in the level of anxiety among smokers during the cessation process, which makes it difficult 
Table 1. Comparison between patients in whom smoking cessation treatment was ultimately successful and those in whom it was not, in terms of the levels of motivation, anxiety, depression, and stress, over the course of a six-month treatment period, in the city of Cuiabá, Brazil, 2013.

\begin{tabular}{|c|c|c|c|c|c|c|c|c|}
\hline \multirow[t]{3}{*}{ Variable } & \multirow{3}{*}{$\begin{array}{l}\text { Time } \\
\text { (days) }\end{array}$} & \multirow[t]{3}{*}{ Category } & \multicolumn{4}{|c|}{ Treatment outcome } & \multirow[t]{3}{*}{$\Delta^{\mathrm{a}}$} & \multirow[t]{3}{*}{ p } \\
\hline & & & \multicolumn{2}{|c|}{ Failure } & \multicolumn{2}{|c|}{ Success } & & \\
\hline & & & $\mathbf{n}$ & $\%$ & $\mathbf{n}$ & $\%$ & & \\
\hline \multirow[t]{6}{*}{ Motivation $^{\mathrm{b}}$} & 0 & Precontemplation/contemplation & 52 & 85.24 & 61 & 75.31 & -9.94 & 0.132 \\
\hline & & Preparation/action & 9 & 14.75 & 20 & 24.69 & & \\
\hline & 45 & Precontemplation/contemplation & 17 & 27.87 & 4 & 4.94 & -22.93 & $<0.001^{*}$ \\
\hline & & Preparation/action & 44 & 72.13 & 77 & 95.06 & & \\
\hline & 180 & Precontemplation/contemplation & 25 & 40.98 & 0 & 0.00 & -40.98 & $<0.001^{*}$ \\
\hline & & Preparation/action & 36 & 59.02 & 81 & 100 & & \\
\hline \multirow[t]{6}{*}{ BAI } & 0 & Moderate/severe & 28 & 45.90 & 26 & 32.10 & -13.80 & 0.093 \\
\hline & & Minimum/mild & 33 & 54.10 & 55 & 67.90 & & \\
\hline & 45 & Moderate/severe & 19 & 31.15 & 12 & 14.81 & -16.34 & 0.022 \\
\hline & & Minimum/mild & 42 & 68.85 & 69 & 85.19 & & \\
\hline & 180 & Moderate/severe & 19 & 31.15 & 10 & 12.35 & -18.80 & 0.007 \\
\hline & & Minimum/mild & 42 & 68.85 & 71 & 87.65 & & \\
\hline \multirow[t]{6}{*}{ BDI } & 0 & Moderate/severe & 22 & 36.07 & 21 & 25.92 & -10.15 & 0.196 \\
\hline & & Minimum/mild & 39 & 63.93 & 60 & 74.08 & & \\
\hline & 45 & Moderate/severe & 21 & 34.42 & 12 & 14.81 & -19.61 & 0.007 \\
\hline & & Minimum/mild & 40 & 65.58 & 69 & 85.19 & & \\
\hline & 180 & Moderate/severe & 17 & 27.87 & 8 & 9.88 & -17.99 & 0.007 \\
\hline & & Minimum/mild & 44 & 72.13 & 73 & 90.12 & & \\
\hline \multirow[t]{6}{*}{ ISSL } & 0 & Stress & 42 & 68.85 & 51 & 62.96 & -5.89 & 0.461 \\
\hline & & No stress & 19 & 31.15 & 30 & 37.04 & & \\
\hline & 45 & Stress & 36 & 59.02 & 39 & 48.15 & -10.87 & 0.195 \\
\hline & & No stress & 25 & 40.98 & 42 & 51.85 & & \\
\hline & 180 & Stress & 38 & 62.30 & 38 & 46.91 & -15.39 & 0.065 \\
\hline & & No stress & 23 & 37.70 & 43 & 53.09 & & \\
\hline
\end{tabular}

BAI: Beck Anxiety Inventory; BDI: Beck Depression Inventory; and ISSL: Inventário de Sintomas de Stress para Adultos de Lipp (ISSL, Lipp Inventory of Stress Symptoms for Adults). 'astimated difference between proportions. bStage of change (level of motivation for change), as assessed with the University of Rhode Island Change Assessment scale. *Fisher's exact test.

to draw comparisons between our results and those of other authors. Although one study reported a similar reduction in patient anxiety during smoking cessation, that study involved only one patient. ${ }^{(24)}$ In addition, we found that the difference between the patients who succeeded in quitting smoking and those who did not, in terms of the level of anxiety, was greater at E3 than at E1. Other studies involving patients in smoking cessation programs have shown that post-treatment anxiety levels are lower in those who were able to stop smoking than in those who continued to smoke. ${ }^{(25-27)}$ In contrast, another study showed that smoking cessation results in an increase in the level of patient anxiety. ${ }^{(28)}$ The relationship between smoking and anxiety is quite complex. In comparison with the general population, individuals with anxiety disorders are twice as likely to smoke, and these disorders are more common in smokers than in nonsmokers. ${ }^{(4,29)}$ One of the reasons cited for this association is that smoking can be a way of self-medicating oneself to treat anxiety symptoms, because nicotine reduces negative emotions and is anxiolytic. ${ }^{(30,31)}$ Furthermore, anxious smokers have greater difficulty in abandoning their dependence, thus showing high rates of relapse and treatment failure. ${ }^{(4,29,30)}$ Anxiety can be defined as an emotional state, with psychological and physiological components, which is part of the normal spectrum of human experience and motivates performance. It can be pathological when it is disproportionate to the situation that triggers it or when it is directed at a subject that does not exist. ${ }^{(32)}$ Therefore, it is important to remember the role that anxiety plays in smokers during the smoking cessation process and to attempt to help them overcome these symptoms.

As with anxiety, we found that the severity of patient depression, as quantified by the BDI score, was also lower after smoking cessation treatment. That outcome is likely attributable to the combined effects of the pharmacological treatment (with bupropion, which is an antidepressant) and the CBT. The pharmacological treatment functions as an adjuvant to the behavioral approach at the stage during which smokers show symptoms of withdrawal syndrome, because it facilitates the approach to the patients, who have been gradually encouraged and counseled to deal with their dependence and to try to break the conditioned 
associations made with cigarettes. ${ }^{(5)}$ Research has shown that quitting smoking does not increase the risk of developing a mental health problem, ${ }^{(25,27,33)}$ which supports our finding that, over the course of treatment, BDI scores were lower among the patients in whom the treatment was ultimately successful. The broad category of depression includes a variety of disorders, such as major depressive disorder, dysthymia, and bipolar depression. Although comorbidity between smoking and depression has been documented, the mechanisms of that association are controversial, because biological, psychological, and social factors could be contributing factors. ${ }^{(34)}$ However, there is strong evidence of comorbidity between smoking and depressive disorders, and many individuals who suffer from depression use nicotine to alleviate their symptoms. ${ }^{(30,34)}$

We found that, like those of anxiety and depression, the level of patient stress also decreased significantly over the course of smoking cessation treatment. It seems that, after the initial phase of the cessation process, when withdrawal symptoms are most pronounced, patient stress levels can be reduced. It is known that the prevalence of stress is higher in smokers than in nonsmokers. ${ }^{(35)}$ Smokers claim that smoking is relaxing and alleviates stress. This is reported as one of the main reasons for smoking, which is considered a true anesthetic for feelings and emotional conflicts. ${ }^{(36)}$ Paradoxically, although smokers report that smoking helps them relax, stress levels are higher in smokers than in nonsmokers. In addition, nicotine dependence increases stress, and the apparent relaxing effect of smoking is rapid and transient, reflecting only the circulating level of the drug. Soon after smoking (when the nicotine has been metabolized), tension and irritability return, making smokers feel the need to return to the consumption of the drug to become relaxed again. ${ }^{(35)}$ However, despite the increased stress levels in the initial period of the cessation process, patients become less stressed after 14 days of abstinence. (37) Over the course of the present study, we observed an absolute increase in the differences between the patients in whom the treatment was ultimately successful and those in whom it was not, in terms of the level of stress, although the association was not statistically significant.

The most important limitation of our study is the lack of data on the proportional contributions of drug therapy and CBT to the results obtained. Further studies, involving control groups to determine the effects that the different forms of intervention have on the variables studied here, are warranted.

We can conjecture that CBT played an important role in our results, because the variables modified by the interventions applied were again measured after the end of the intervention, giving the impression that it was really behavioral change and not only the chemical effects of the drug, which disappear a few days after the end of the drug therapy regimen. In addition, the cessation of smoking, per se, can reduce levels of anxiety, depression, and stress, ${ }^{(26)}$ making it a factor with an additive effect that could have contributed to the improvements observed in our study, in which there were reductions in the levels of anxiety, depression, and stress, as well as increased motivation, over the course of treatment, changes that were more pronounced among the patients in whom the treatment was ultimately successful (i.e., those who quit smoking).

Our findings indicate that the great majority of smokers begin the smoking cessation process with low motivation, and that this changes after the interventions have been applied within the cessation program. The effects of medications (diminishing withdrawal symptoms), combined with CBT and with the techniques applied in order to bring about change in the behavior of smokers, appear to be decisive for the success or failure of smoking cessation treatment.

\section{REFERENCES}

1. World Health Organization [homepage on the Internet]. Geneva: World Health Organization [cited 2014 Dec 1]. Global status report on noncommunicable diseases 2010. [Adobe Acrobat document, 176p.]. Available from: http://www.who.int/nmh/publications/ncd report2010/en/

2. Levy D, de Almeida LM, Szklo A. The Brazil SimSmoke policy simulation model: the effect of strong tobacco control policies on smoking prevalence and smoking-attributable deaths in a middle income nation. PLoS Med. 2012;(9)11:e1001336. http://dx.doi. org/10.1371/journal.pmed.1001336

3. Reichert J, Araújo AJ, Gonçalves CM, Godoy I, Chatkin JM, Sales MP, et al. Smoking cessation guidelines-2008. J Bras Pneumol. 2008;34(10):845-80. http://dx.doi.org/10.1590/S180637132008001000014

4. Piper ME, Cook JW, Schlam TR, Jorenby DE, Baker TB. Anxiety diagnoses in smokers seeking cessation treatment: relations with tobacco dependence, withdrawal, outcome and response to treatment. Addiction. 2011;106(2):418-27. http://dx.doi.org/10.1111/ j.1360-0443.2010.03173.x

5. Martins KC, Seidl EM. Mudança do comportamento de Fumar em participantes de grupos de Tabagismo. Psic Teor Pesq

\section{$2011 ; 27(1): 55-64$}

6. Pereira LF. O que é terapia estendida e quando poderá ser indicada? In: Araújo AJ, editor. Manual de Condutas e Práticas em Tabagismo - Sociedade Brasileira de Pneumologia e Tisiologia. São Paulo: AC Farmacêutica; 2012.

7. Brasil. Ministério da Saúde. Instituto Nacional de Câncer Coordenação de Prevenção e Vigilância. Divisão de Controle do Tabagismo e Outros Fatores de Risco de Câncer. Deixando de Fumar sem Mistérios-Manual do Coordenador. Rio de Janeiro: Instituto Nacional de Câncer; 2005

8. Fagerström KO. Measuring degree of physical dependence to tobacco smoking with reference to individualization of treatment. Addict Behav. 1978;3(3-4):235-41. http://dx.doi.org/10.1016/03064603(78)90024-2

9. Carmo JT, Pueyo AA. A adaptação ao português do Fagerström test for nicotine dependence (FTND) para avaliar a dependência tolerância à nicotina em fumantes brasileiros. Rev Bras Med. 2002 59(1/2):73-80.

10. McConnaughy EA, DiClemente CC, Prochaska JO, Velicer WF. Stages of change in psychotherapy: a follow up report. Psychotherapy. 
1989;26(4):494-503. http://dx.doi.org/10.1037/h0085468

11. Szupszynski KP, Oliveira MS. Adaptação brasileira da University of Rhode Island Change Assessment (URICA) para usuários de substâncias ilícitas. Psico-USF. 2008;13(1):31-9.

12. Beck AT, Epstein N, Brown G, Steer RA. An Inventory for measuring clinical anxiety: psychometric properties. J Consult Clin Psychol. 1988;56(6):893-7. http://dx.doi.org/10.1037/0022-006X.56.6.893

13. Cunha JA. Manual da versão em português das Escalas Beck. São Paulo: Casa do Psicólogo; 2001.

14. Beck AT, Ward CH, Mendelson M, Mock J, Erbaugh J. An Inventory for Measuring Depression. Arch Gen Psychiat. 1961;4:561-71. http:// dx.doi.org/10.1001/archpsyc.1961.01710120031004

15. Lipp, MN. Manual do Inventário de Sintomas de Stress para Adultos de Lipp (ISSL). São Paulo: Casa do Psicólogo; 2000.

16. Siegel $\mathrm{S}$, Castellan NJ. Estatística não-paramétrica para ciências do comportamento. 2nd ed. São Paulo: Artmed; 2006.

17. Siqueira LS, Tibúrcio JD. Estatística na área da Saúde: Conceitos, metodologia, aplicações e prática computacional. Belo Horizonte: Coopmed; 2011

18. Costa Neto PL. Estatística. 2nd ed. São Paulo: E Blucher Ltda.; 2005

19. Silva ST, Martins MC, Faria RF, Cotta RM. Combating smoking in Brazil: the strategic importance of government actions. Ciên Saúde Colet. 2014;19(2):539-52

20. Russo AC, Azevedo RC. Factors that motivate smokers to seek outpatient smoking cessation treatment at a university general hospital. J Bras Pneumol. 2010;36(5):603-11. http://dx.doi. org/10.1590/S1806-37132010000500012

21. Miller WR, Rollnick S. Entrevista motivacional: preparando as pessoas para a mudança de comportamentos adictivos. Porto Alegre: Artes Médicas; 2001.

22. Miller WR, Sanchez VC. Motivating Young adults for treatment and lifestyle change. In: Howard, G, editor. Issues in alcohol use and misuse by young adults. Notre Dame: University of Notre Dame; 1993. p. 55-82.

23. Prochaska, JO, Diclemente CC, Norcross JC. In search of how people change: applications to addictive behaviors. Am Psychol. 1992;47:102-14. http://dx.doi.org/10.1037/0003-066X.47.9.1102

24. Mundim MM, Bueno GN. Behavioral analysis in a case of dependence to the nicotine. Rev Bras Ter Comport Cogn. 2006;8(2):179-81.

25. Mathew AR, Robinson JD, Norton PJ, Cinciripini PM, Brown RA, Blalock JA. Affective trajectories before and after a quit attempt in smokers with current depressive disorders. Nicotine Tob Res. 2013;15(11):1807-15. http://dx.doi.org/10.1093/ntr/ntt036

26. Taylor G, McNeill A, Girling A, Farley A, Lindson-Hawley N, Aveyard
P. Change in mental health after smoking cessation: systematic review and meta-analysis. BMJ. 2014;348:g1151. http://dx.doi. org/10.1136/bmj.g1151

27. Cavazos-Rehg PA, Breslau N, Hatsukami D, Krauss MJ, Spitznagel EL, Grucza, RA, et al. Smoking cessation is associated with lower rates of mood/anxiety and alcohol use disorder. Psychol Med. 2014:44(12):2523-35. http://dx.doi.org/10.1017/ S0033291713003206

28. Beco-a E, Vázquez FL, del Carmen Míguez M. Smoking cessation and anxiety in a clinical sample. Pers Individ Dif. 2002;32:489-94. http://dx.doi.org/10.1016/S0191-8869(01)00050-2

29. Mykletun A, Overland S, Aarø LE, Liabø HM, Stewart R. Smoking in relation to anxiety and depression: Evidence from a large population survey: The Hunt Study. Eur Psychiatry. 2008;23(2):77-84. http:// dx.doi.org/10.1016/j.eurpsy.2007.10.005

30. Urdapilleta-Herrera EC, Sansores RH, Ramírez-Venegas A, MéndezGuerra M, Lara-Rivas AG, Guzmán-Barragán SA, et al. Ansiedad y depresión en fumadores mexicanos y su relación con el grado de adicción. Salud Pública Méx. 2010;52(2):120-7. http://dx.doi. org/10.1590/s0036-36342010000800007

31. Edwards AC, Kendler KS. Nicotine withdrawal-induced negative affect is a function of nicotine dependence and not liability to depression or anxiety. Nicotine Tob Res. 2011:13(8):677-85. http:// dx.doi.org/10.1093/ntr/ntr058

32. Andrade LH, Gorenstein $\mathrm{C}$. General aspects of anxiety rating scales. Rev Psiquiatr Clin. 1998;25(6):285-90.

33. Donald $\mathrm{S}$, Chartrand $\mathrm{H}$, Bolton JM. The relationship between nicotine cessation and mental disorders in a nationally representative sample. J Psychiatr Res 2013;47(11):1673-9. http://dx.doi.org/10.1016/1. jpsychires.2013.05.011

34. Gigliotti AP, Lemos T. Quais as características das comorbidades psiquiátricas e do tabagismo: depressão, ansiedade e esquizofrenia? In: Araújo AJ, editor. Manual de Condutas e Práticas em Tabagismo - Sociedade Brasileira de Pneumologia e Tisiologia. São Paulo: AC Farmacêutica; 2012

35. Rosemberg J. Nicotina: droga Universal. São Paulo: Secretaria de Estado da Saúde de São Paulo/Centro de Vigilância Epidemiológica; 2003. [cited 2014 Dec 1]. Available from: ftp://ftp.cve.saude.sp.gpv br/doc_tec/cronicas/nicotina.pd

36. Ivings K. Livre-se do cigarro - um plano para aniquilar o vício em nicotina. São Paulo: Madras; 2009.

37. Fitzpatrick P. Using tobacco does not reduce stress, researchers report. [monograph on the Internet]. Washington: United States Air Force; 2011 [cited 2014 Dec 1]. Available from: http://www.af.mil/ News/ArticleDisplay/tabid/223/Article/113470/using-tobacco-doesnot-reduce-stress-researchers-report.aspx 